Jumal Sosiafisasi

Jurnal Hasil Pemikiran, Penelitian, dan Pengembangan

Keilmuan Sosiologi Pendidikan

Vol 8, Nomor 1, Maret 2021

\title{
PELESTARIAN AKULTURASI ADAPTASI BUDAYA MAPALUS DAERAH MINAHASA SULAWESI UTARA
}

\author{
Nismawati $^{1}$, Cahyadi Nugroho ${ }^{2}$ \\ ${ }^{1}$ Program Studi Pendidikan Sosiologi, Fakultas Ilmu Sosial, Universitas Negeri Manado \\ ${ }^{2}$ Jurusan Pendidikan Geografi, Fakultas Ilmu Sosial, Universitas Negeri Manado \\ nismawati@unima.ac.id ${ }^{1}$, cahyadinugroho@unima.ac.id ${ }^{2}$
}

\begin{abstract}
ABSTRAK
Budaya Mapalus yang merupakan budaya yang sudah menjadi kegiatan sehari-hari masyarakat Minahasa. Penelitian ini bertujuan untuk mengupayakan pelestariannya melalui akulturasi adaptasi budaya. Data penelitian dianalisis dengan metode kualilatif melalui observasi, wawancara dan dokumentasi. Data akan diolah dengan melalui analisis SWOT dan model kebijakan melalui analisis AHP. Berdasarkan hasil analisis SWOT strategi pelestarian Budaya Mapalus yang adaptif, yaitu (1) pembentukan kelompokkelompok Mapalus yang diintegrasikan dengan perkembangan global, (2) integrasi pemerintah daerah dengan lembaga masyarakat dalam menjaga keutuhan Budaya Mapalus, (3) filtrasi budaya yang sesuai dengan hakikat Budaya Mapalus, (4) kaderisasi masyarakat untuk melestarikan Budaya Mapalus melalui kegiatan partisipatif, (5) penanaman esensi Budaya Mapalus dalam diri masing-masing individu melalui kegiatan pelatihan dan penyuluhan secara berkala, dan (6) membuat agenda kegiatan yang melibatkan masyarakat untuk berperan aktif sesuai dengan norma yang terkandung pada Budaya Mapalus. Model kebijakan awal yang harus ditempuh dari hasil analisis AHP adalah penanaman esensi Budaya Mapalus dalam diri masing-masing individu melalui kegiatan pelatihan dan penyuluhan.
\end{abstract}

Kata kunci: Pelestarian, Akulturasi, Adaptasi, Budaya Mapalus, Minahasa.

\begin{abstract}
The Mapalus culture is a culture that has become a daily activity for the Minahasa people. This study aims to seek its preservation through acculturation of cultural adaptation. The research data were analyzed using a qualitative method through observation, interviews and documentation. The data will be processed through SWOT analysis and policy models through AHP analysis. Based on the results of the SWOT analysis of the adaptive Mapalus Culture preservation strategy, namely (1) the formation of Mapalus groups that are integrated with global developments, (2) integration of local governments with community institutions in maintaining the integrity of Mapalus Culture, (3) cultural filtration in accordance with its nature Mapalus Culture, (4) community regeneration to preserve Mapalus Culture through participatory activities, (5) inculcating the essence of Mapalus Culture in each individual through regular training and counseling activities, and (6) creating an activity agenda that involves the community to play an active role in accordance with the norms contained in the Mapalus Culture. The initial policy model that must be adopted from the results of the AHP analysis is the cultivation of the essence of Mapalus Culture in each individual through training and counseling activities.
\end{abstract}

Keywords: Preservation, Acculturation, Adaptation, Mapalus Culture, Minahasa.

\section{PENDAHULUAN}

Secara fundamental, Mapalus adalah suatu bentuk gotong royong tradisional yang memiliki perbedaan dengan bentuk-bentuk gotong royong modern, misalnya: perkumpulan atau asosiasi usaha. Secara filosofis, Mapalus mengandung makna dan arti yang sangat mendasar. Mapalus sebagai local spirit and local wisdom Masyarakat Minahasa yang terpatri dan berkohesi di dalamnya: 3 (tiga) jenis hakikat dasar pribadi manusia dalam kelompoknya, yaitu: Touching Hearts, Teaching Mind, dan Transforming Life. Mapalus adalah hakikat dasar dan aktivitas kehidupan orang Minahasa (Manado) yang terpanggil 
dengan ketulusan hati nurani yang mendasar dan mendalam (touching hearts) dengan penuh kesadaran dan tanggung jawab menjadikan manusia dan kelompoknya (teaching mind) untuk saling menghidupkan dan menyejahterakan setiap orang dan kelompok dalam komunitasnya (transforming life). Mapalus berarti tolong menolong karena seseorang telah menerima sokongan ia akan memberikan pertolongan (Uada et al., 2018) (Kalangi, 1971).

Namun seiring perkembangan zaman, nilai budaya mapalus mulai bergeser sedikit demi sedikit. Faktor perkembangan, teknologi serta perkembangan perekonomian masyarakat adalah tiga faktor yang dominan untuk saat ini sebagai faktor yang menyebabkan terjadinya pergeseran pada budaya mapalus (Potabuga, 2012). Menurut (WAWOINTANA \& Putra, 2001) penyebab perubahan mapalus bersumber dari dua faktor yaitu faktor intern dan faktor ekstern. Faktor intern ialah faktor yang berasal dari dalam, yang secara fisik ialah ada pengaruh dari sistem organisasi mapalus, jumlah anggota, tingkat sosial ekonomi yang bergeser, lingkungan tempat mapalus itu hidup; dan secara psikis ialah pola pikir anggota. Faktor ekstern ialah faktor yang berasal dari luar, yakni faktor penyebab secara fisik dan psikis. Secara fisik ialah perubahan dan pergeseran waktu, lokasi, iptek, inforrnasi, ekonomi, dan sosial budaya. Faktor ekstern secara psikis ialah, pengaruh sikap hidup, nilainilai kehidupan atau norma-norma kemasyarakatan, dan cara berpikir manusia. (KAREPOWAN, 2014) menambahkan bahwa faktor-faktor yang mempengaruhi pergeseran nilai sosial budaya Mapalus adalah faktor materialisme, nilai individualistik, faktor pendidikan.

Penelitian ini didasari dengan kekhawatiran kepada generasi yang akan datang yang selalu mengikuti perkembangan atau era teknologi masa kini. Generasi saat ini, khususnya masyarakat Minahasa yang masih terbilang muda banyak mengalami degradasi kebudayaan. Budaya Mapalus yang merupakan budaya yang sudah menjadi kegiatan sehari-hari masyarakat Sejak munculnya globalisasi, budaya Minahasa mulai tergerus akibat berkembangnya teknologi dan modernisasi. Sehingganya, penelitian ini dilaksanakan untuk menjawab permasalahan tentang Budaya Mapalus yang saat ini mulai tergeser keberadaannya di dalam diri masyarakat Minahasa.

\section{METODE PENELITIAN}

Data penelitian dianalisis dengan metode kualilatif melalui observasi, wawancara dan dokumentasi. Data akan diolah dengan melalui analisis SWOT (Faktor Internal dan Eksternal) dan model kebijakan melalui analisis AHP (Analytical Hierarchy Process).

\section{HASIL PENELITIAN DAN PEMBAHASAN}

\section{Kondisi Budaya Mapalus di Kabupaten Minahasa}

Budaya mapalus merupakan budaya lokal masyarakat Minahasa, Sulawesi Utara. Budaya mapalus identik dengan "torang samua basudara" yang artinya kita semua bersaudara. Lebih gamblangnya, budaya mapalus diperkenalkan sebagai suatu kebiasaan atau habit kegotongroyongan antar satu dengan yang lainnya. Sikap kegotongroyongan masyarakat Minahasa yang terbungkus dalam budaya mapalus menggambarkan kebersamaan masyarakat dalam segala hal. Mapalus mengandung makna suatu sikap dan tindakan yang didasarkan pada kesadaran akan keharusan untuk beraktivitas dengan menghimpun (mempersatukan) daya (kekuatan dan kepandaian) setiap personil masyarakat untuk memperoleh suatu hasil yang optimal sesuai tujuan yang telah disepakati sebelumnya (Sumual et al., 1995). 
Hasil penelitian menunjukkan dibeberapa lokasi Kabupaten Minahasa, budaya mapalus sepertinya hanya bergerak dalam bidang pertanian, perkebunan dan perihal yang sifatnya untuk pemenuhan kebutuhan ekonomi. Beberapa daerah di minahasa induk lebih memprioritaskan kepentingan pribadinya dibandingkan kegotongroyongan. Budaya mapalus saat ini di Kabupaten Minahasa bisa dibilang sudah termakan zaman, karena masyarakat sudah banyak yang meninggalkan habit atau kebiasaan tersebut karena kurang menguntungkan. Padahal menurut buku, The Mapalus Way, mapalus sebagai sebuah sistem kerja yang memiliki nilai-nilai etos seperti, etos resiprokal, etos partisipatif, solidaritas, responsibilitas, gotong royong, good leadership, disiplin, transparansi, kesetaraan, dan trust (Umbas, 2011).

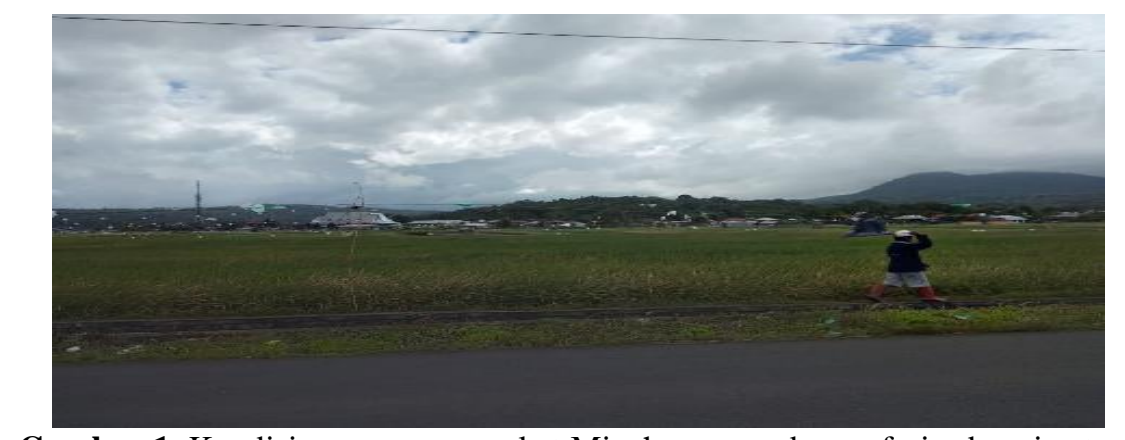

Gambar 1. Kondisi umum masyarakat Minahasa yang berprofesi sebagai petani (Sumber: Dokumentasi Pribadi, 2020)

Bagi sebagian besar masyarakat yang berusia $45+$ masih menjalankan Budaya Mapalus dalam melaksanakan aktivitas kesehariannya, baik itu dalam hal gotongroyong dilingkungan desa, panen bersama, saling meringankan pekerjaan dilingkungan sekitarnya. Mapalus bagi orang Tontemboan disebut maendo. Dalam awalan "ma" dengan kata "endo" yang artinya hari atau matahari. Jadi, maendo artinya mengambil hari atau mempergunakan 5 hari untuk bekerja bersama-sama pada orang lain (Kalempow, 1968).

Masyarakat Minahasa yang masih dikategorikan sebagai remaja sampai dewasa produktif banyak yang merantau. Mereka lebih tertarik untuk mencari penghidupan diluar daerahnya dan tak pulang kembali untuk membangun desanya. Akibatnya Budaya Mapalus saat ini didominasi peranannya oleh para orang dewasa sampai kepada lansia yang menetap di Minahasa. Budaya Mapalus yang seharusnya diregenerasikan kepada penerusnya mengalami pergeseran secara terus-menerus karena kurangnya pendidikan karakter dalam bermasyarakat sehingga Budaya Mapalus ini seakan-akan hanya omongan saja.

\section{Modernisasi yang masuk dalam Budaya Mapalus}

Mapalus bagi orang Tombulu disebut juga mapalus. Kata mapalus merupakan gabungan dari dua kata "ma" berarti sedang mengerjakan sesuatu, "palus" berarti kegiatan bersama dan masing-masing anggota secara bergilir. Bila dirangkaikan kata mapalus berarti bahwa orang-orang yang sedang secara giliran (Turang, 1983).

Modernisasi yang mewabah di masyarakat Minahasa saat ini adalah eksistensi dunia maya. Sebagian besar masyarakat yang tergolong remaja lebih suka mengeksiskan dirinya dibandingkan gotongroyong dengan masyarakat tempat ia tinggal. Padahal mapalus adalah tolong menolong dengan dasar kerja sama untuk mencapai suatu maksud (berbakti untuk kepentingan umum) (Tumenggung, 2019). Beberapa contoh kasus yang kerap terjadi berdasarkan hasil penelitian dilapangan adalah banyak remaja muda-mudi kumpul-kumpul 
mengeksiskan dirinya demi sebuah popularitas. Selain itu, banyak diantaranya generasi muda yang uji kebolehan dengan melakukan balap liar yang meresahkan lingkungan sekitar. Para remaja ini acap kali memamerkan apa yang ia punya untuk menarik lawan jenis ataupun hanya untuk sebuah popularitas. Beberapa diantaranya ada yang tidak patuh kepada orangtua, tidak peka terhadap lingkungan sekitar, jarang berbaur dimasyarakat hingga individualis.

\section{Degradasi Budaya Mapalus}

Mapalus bagi orang Tonsea dan orang Toulour disebut mapalus. Mapalus berasal dari kata "ma" berarti saling, "palus" yang berarti menuang atau memberi. Sehingga dengan demikian kata mapalus berarti saling memberi atau menaung kepada orang yang membutuhkan (Sarajar, 1996). Sikap Mapalus yang saat ini masih terjaga hanya dikalangan orang yang sudah berumur (orangtua). Mereka menerapkan Budaya Mapalus dalam melaksanakan kegiatan hariannya, baik itu dalam pemenuhan kebutuhan ekonomi maupun aktivitas sosial di masyarakat. Hasil lapangan menunjukkan bahwa Budaya Mapalus tidak dijiwai oleh kalangan muda karena dianggap kurang menguntungkan. Sikap ini mencerminkan bahwa generasi muda yang seharusnya mewarisi budaya lokal (Budaya Mapalus) tidak menerima dengan baik apa yang sudah seharusnya menjadi warisan daerah tersebut.

Hasil penelitian menunjukkan generasi muda banyak yang tidak tahu peranannya dimasyarakat sampai pada sejatinya Budaya Mapalus itu sendiri. Mereka lebih asik terhadap dunianya, dunia muda seperti kumpul-kumpul, uji kebolehan, hedonisme, individualisme, acuh tak acuh yang pada hakikatnya mereka tertuju pada kepuasan diri melalui popularitas. Bentukan tersebut merupakan hasil dari modernisasi yang masuk dan tidak difiltrasi dengan baik sehingga secara perlahan mengikis suatu kebiasaan yang seharusnya menjadi jiwa masyarakat Minahasa

\section{Akulturasi Adaptasi Budaya Mapalus}

Manusia dalam konsep moral etik agama tua orang minahasa adalah dalam rangka "Maesaesaan womoleoleosan"/saling mengasihi, persatuan dan kesatuan keseimbangan/harmonis (LUMANTOW et al., 2017) (Siwu, 1986). Menurut (Adam, 1976) mapalus dapat dibentuk secara sukarela oleh individu individu yang berkemauan untuk itu atau dilakukan.

Perpaduan modernisasi dengan Budaya Mapalus sendiri tidak hanya dilandaskan pada suatu teori saja, melainkan sesuai dengan kebutuhan dan kondisi masyarakat Minahasa. Berdasarkan hasil rumusan tentang faktor-faktor internal dan eksternal yang terdapat pada Budaya Mapalus saat ini jika diakulturasikan dengan modernisasi diharapkan dapat memunculkan suatu bentuk strategi yang dapat ditempuh untuk pelestariannya. Adapun bentukan dari faktor-faktor tersebut terlihat pada tabel 1 .

Tabel 1. Faktor-Faktor Analisis SWOT

\begin{tabular}{|c|c|c|}
\hline & $\underline{\text { Kekuatan }(\mathbf{S})}$ & Kelemahan (W) \\
\hline Faktor-Faktor SWOT & $\begin{array}{l}\text { 1. Penanaman sikap } \\
\text { gotongroyong. } \\
\text { 2. Menciptakan rasa }\end{array}$ & $\begin{array}{l}\text { 1. Kurangnya filtrasi budaya } \\
\text { 2. Minimnya kaderisasi untuk } \\
\text { pelestarian budaya }\end{array}$ \\
\hline
\end{tabular}




\begin{tabular}{|c|c|c|}
\hline & $\begin{array}{l}\text { kebersamaan. } \\
\text { Menjaga keseimbangan } \\
\text { lingkungan sosial dan } \\
\text { lingkungan alam. } \\
\text { 4. Kerukunan dan } \\
\text { kenyamanan dalam } \\
\text { bermasyarakat. }\end{array}$ & $\begin{array}{l}\text { Kesadaran diri masyarakat } \\
\text { kurang }\end{array}$ \\
\hline Peluang $(\mathrm{O})$ & $\underline{\text { Strategi S-O }}$ & $\underline{\text { Strategi W-O }}$ \\
\hline $\begin{array}{l}\text { Kemudahan dalam } \\
\text { pemenuhan kebutuhan } \\
\text { ekonomi maupun sosial. } \\
\text { 2. Menjadikan budaya yang } \\
\text { adaptif. } \\
\text { 3. Meningkatkan income } \\
\text { pemerintah daerah }\end{array}$ & $\begin{array}{l}\text { Pembentukan kelompok- } \\
\text { kelompok Mapalus yang } \\
\text { diintegrasikan dengan } \\
\text { perkembangan global. } \\
\text { 2. Integrasi pemerintah daerah } \\
\text { dengan lembaga } \\
\text { masyarakat dalam menjaga } \\
\text { keutuhan Budaya Mapalus. }\end{array}$ & $\begin{array}{l}\text { Filtrasi budaya yang sesuai } \\
\text { dengan hakikat Budaya } \\
\text { Mapalus. } \\
\text { 2. Kaderisasi masyarakat } \\
\text { untuk melestarikan Budaya } \\
\text { Mapalus melalui kegiatan } \\
\text { partisipatif. }\end{array}$ \\
\hline Ancaman (T) & Strategi S-T & Strategi W-T \\
\hline $\begin{array}{l}\text { 1. Individualisme } \\
\text { masyarakat. } \\
\text { 2. Perubahan tatanan sosial. } \\
\text { 3udaya baru menggeser } \\
\text { budaya lama. }\end{array}$ & $\begin{array}{l}\text { Penanaman esensi Budaya } \\
\text { Mapalus dalam diri masing- } \\
\text { masing individu melalui } \\
\text { kegiatan pelatihan dan } \\
\text { penyuluhan secara berkala. }\end{array}$ & $\begin{array}{l}\text { Membuat agenda kegiatan } \\
\text { yang melibatkan masyarakat } \\
\text { untuk berperan aktif sesuai } \\
\text { dengan norma yang } \\
\text { terkandung pada Budaya } \\
\text { Mapalus. }\end{array}$ \\
\hline
\end{tabular}

Sumber: Olahan Penelitian, 2020

Berdasarkan hasil analisis SWOT yang tergambar pada tabel 1 dari beberapa faktor internal dan eksternal yang didapat dilapangan, maka terbentuklah 6 rekomendasi atau strategi yang dapat diimplementasikan untuk pelestarian Budaya Mapalus yang adaptif, yaitu:

a. Pembentukan kelompok-kelompok Mapalus yang diintegrasikan dengan perkembangan global (A1).

b. Integrasi pemerintah daerah dengan lembaga masyarakat dalam menjaga keutuhan Budaya Mapalus (A2).

c. Filtrasi budaya yang sesuai dengan hakikat Budaya Mapalus (A3).

d. Kaderisasi masyarakat untuk melestarikan Budaya Mapalus melalui kegiatan partisipatif (A4).

e. Penanaman esensi Budaya Mapalus dalam diri masing-masing individu melalui kegiatan pelatihan dan penyuluhan secara berkala (A5).

f. Membuat agenda kegiatan yang melibatkan masyarakat untuk berperan aktif sesuai dengan norma yang terkandung pada Budaya Mapalus (A6).

Pelestarian Budaya Mapalus yang adaptif dapat dilakukan dengan berbagai cara diantaranya adalah dengan membentuk suatu kebijakan awal yang dapat ditempuh untuk menggiatkan Budaya Mapalus didalam diri masyarakat Minahasa. Pembentukan kebijakan dihasilkan dari beberapa rumusan yang diusulkan melalui analisis 
sebelumnya yaitu analisis SWOT yang merupakan alternatif kebijakan yang akan dijalankan dengan kode A1 sampai A6. Kemudian hasil rumusan analisis SWOT dilakukan FGD (Focus Group Discussion) bersama para pakar sosiologi untuk membentuk priority yang akan diolah melalui AHP (Analytical Hierarchy Process).

Masing-masing alternatif akan dinilai berdasarkan kekuatan (Strengthness), kelemahan (weaknesess), peluang (opportunity) dan ancaman (threatness). Hasil keseluruhan yang telah dianalisis melalui AHP dari masing-masing aspek SWOT tergambar pada grafik dibawah ini.

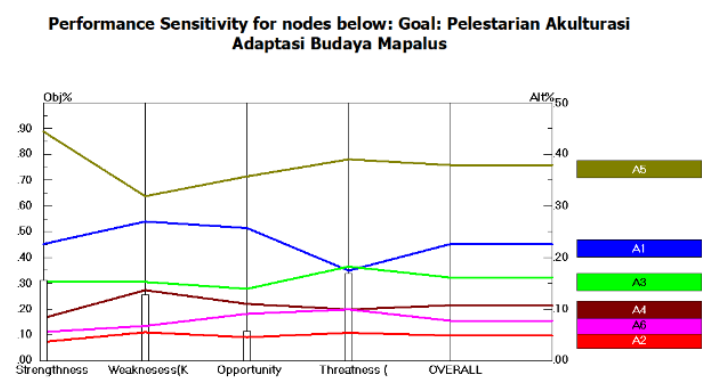

Gambar 2. Grafik Hasil Sintesis SWOT melalui AHP (Sumber: Olahan Penelitian, 2020)

Hasil tersebut menunjukkan bahwa dari keseluruhan aspek alternatif 5 (A5) yaitu penanaman esensi Budaya Mapalus dalam diri masing-masing individu melalui kegiatan pelatihan dan penyuluhan secara berkala memiliki kontribusi yang sangat tinggi dibandingkan dengan alternatif lainnya. Hal tersebut dikarenakan esensi dari Budaya Mapalus sendiri belum tercermin dari masing-masing individu sehingga langkah ini tepat untuk dilaksanakan melalui kegiatan penyuluhan, pelatihan ataupun kegiatan sosial lainnya. Jika esensi Budaya Mapalus itu sudah menjadi jiwa dari masing-masing masyarakat Minahasa maka masyarakat tersebut sudah menerapkan nilai-nilai budaya lokal didaerahnya.

Perlu juga ditekankan bahwa Budaya Mapalus tidak hanya sekedar wacana saja atau hanya pemberian penyuluhan ataupun kegiatan melainkan perlu diikuti dengan aksi seperti kegiatan sosial partisipatif dalam bentuk kelompok-kelompok kecil. Bentukan kelompok ini didampingi dan selalu diarahkan melalui baik itu pemerintah, tokoh adat, tokoh agama, tokoh masyarakat, kerabat atau keluarga untuk selalu menjunjung tinggi budayanya. Hal tersebut dikarenakan jika suatu budaya global yang mengharuskan masyarakat Minahasa untuk merubah atau mengikis Budaya Mapalus bisa memfilter diri sebagai seorang individu ataupun dalam kelompok masyarakat (Nismawati \& Nugroho, 2020). Setelah menanamkan esensi Budaya Mapalus, membentuk kelompokkelompok Mapalus, dan mampu memfilterisasi budaya maka masyarakat khusnya tokoh-tokoh yang berperan dalam pelestarian budaya perlu mengkaderasisasi para generasi muda untuk sama-sama melestarikan Budaya Mapalus yang merupakan warisan dan identitas dari masyarakat Minahasa baik itu melalui kegiatan partisipatif maupun membangun relasi dengan para stakeholder untuk menunjang kelestarian budaya.

Terakhir, peranan Pemerintah Daerah dalam membangun kelestarian Budaya Mapalus tidak boleh lepas. Pemerintah Daerah harus bisa mendukung kegiatan-kegiatan dimasyarakat yang mencerminkan Budaya Mapalus tentunya yang tidak melanggar UUD 1945 dan Pancasila. Selain itu, Pemerintah Daerah Mampu merangkul masyarakat untuk saling menjaga kelestarian Budaya Mapalus yang hingga kini keberadaannya 
mulai terkikis oleh modernisasi. Inovasi dan kreatiitas sangat diperlukan untuk mengembalikan jati diri masyarakat Minahasa untuk menjadikan masyarakat manusia yang sesungguhnya.

\section{PENUTUP}

Perkembangan budaya global saat ini memiliki dampak yang sangat besar terhadap budaya lokal. Budaya lokal yang merupakan identitas suatu daerah atau wilayah akan terkikis dan menghilang keberadaannya jika tidak adanya pelestarian budaya melalui proses sosial. Proses sosial akan memberikan dampak yang besar terhadap budaya lokal apakah budaya lokal akan bergeser atau bertahan. Proses sosial juga bisa mengarahkan suatu budaya lokal untuk terus eksis dengan perkembangan global yang dikenal dengan adaptasi budaya. Adaptasi budaya sama hal nya dengan identitas diri yang dipadukan dengan perkembangan global tanpa menghilangkan esensi dari budaya tersebut.

Budaya Mapalus merupakan budaya yang sudah turun-temurun diwariskan dari generasi ke generasi untuk sama-sama membangun daerahnya. Tidak hanya sampai disitu, Budaya Mapalus mencerminkan sikap gotongroyong, saling, menjaga saling memiliki saling rukun dan saling menciptakan rasa aman dalam kehidupan bermasyarakat. Budaya Mapalus mengajarkan untuk membentuk manusia menjadi manusia yang sesungguhnya. Dalam mewujudkan hal tersebut, Budaya Mapalus harus dilestarikan dengan berbagai upaya. Salah satu upaya yang dapat dilakukan adalah membentuk Budaya Mapalus yang adaptif. Pada hasil penelitian dilapangan banyak terdapat banyak problematika khususnya berkaitan dengan Budaya Mapalus. Kondisi masyarakat Minahasa saat ini cenderung individualis, pasif di masyarakat, hanya eksis di dunia maya dan mengesampingkan esensi dari Budaya Mapalus yang merupakan jati diri masyarakat Minahasa. Jika hal ini terus merebak dalam diri seorang manusia di masyarakat, maka Budaya Mapalus akan lenyap dengan sendirinya dan identitas masyarakat Minahasa sudah bercampur baur dengan modernisasi.

Untuk mengantisipasi terjadinya hal tersebut, maka perlu pelestarian Budaya Mapalus yang adaptif agar dapat menyesuaikan dengan perkembangan global dan tidak menghilangkan esensi dari Budaya Mapalus. Beberapa langkah yang dapat ditempuh melalui pengambilan kebijakan yang tepat. Hasil penelitian menunjukkan bahwa langkah awal kebijakan yang dapat diambil untuk melestarikan Budaya Mapalus yang adaptif adalah dengan menanamkan esensi Budaya Mapalus dalam diri masing-masing individu melalui kegiatan pelatihan dan penyuluhan secara berkala. Hal tersebut dilakukan mengingat kondisi individu masyarakat Minahasa yang belum mencerminkan budayanya sendiri untuk menjadikannya manusia yang sesungguhnya.

\section{DAFTAR PUSTAKA}

Adam, L. (1976). Adat Istiadat Suku Bangsa Minahasa. Bhratara.

Kalangi. P. 1971. Kebudayaan Minahasa. Jakarta: Berita Antropologi Jilid II No. 4

KAREPOWAN, Z. Y. (2014). Peningkatan Disiplin Melalui Kegiatan Mapalus Dalam Budaya Minahasa. Jurnal Pendidikan Usia Dini, 8(1), 65-72.

LUMANTOW, M. E., Tampi, G. B., \& Londa, V. Y. (2017). Pengaruh budaya Mapalus Terhadap Partisipasi Masyarakat Dalam Pembangunan Di Desa Tombasian Atas Kecamatan Kawangkoan Barat Kabupaten Minahasa. JURNAL ADMINISTRASI PUBLIK, 3(046). 
Jumal Sosiafisasi

Jurnal Hasil Pemikiran, Penelitian, dan Pengembangan Keilmuan Sosiologi Pendidikan

Vol 8, Nomor 1, Maret 2021

Nismawati, N., \& Nugroho, C. (2020). PEREKONOMIAN MASYARAKAT KELURAHAN TOUNSARU PASCA MEREBAKNYA WABAH COVID-19. Indonesian Journal of Economics, Entrepreneurship, and Innovation. https://doi.org/10.31960/ijoeei.v1i1.441

Potabuga, J. (2012). KAJIAN BUDAYA MAPALUS DI KECAMATAN DUMOGA TIMUR KABUPATEN BOLAANG MONGONDOW.

Sarajar, H. M. (1996). Persepsi masyarakat terhadap mapalus di daerah Sulawesi Utara. Departemen Pendidikan dan Kebudayaan, Direktorat Jenderal Kebudayaan ....

Sumual, H. N., Supit, B., \& Matindas, B. E. (1995). Baku beking pande: sebuah keputusan falsafi. Bina Insani.

Tumenggung, M. (2019). Beberapa Analisa Perbandingan Mapalus dan Gotong Royong. Antropologi Indonesia, 58-73.

Turang, J. (1983). Mapalus di Minahasa (Mapalus at Minahasa), Posko Operasi Mandiri (Mapalus at Minahasa). Daerah Tingkat II Kabupaten Minahasa. Tomohon.

Uada, H., Kandowangko, N., \& Goni, S. Y. V. I. (2018). BUDAYA MAPALUS DALAM MENINGKATKAN AKTIVITAS KELOMPOK TANI (Suatu Studi di Desa Talawaan Atas Kecamatan Wori Kabupaten Minahasa Utara). HOLISTIK, Journal Of Social and Culture.

Umbas, V. (2011). Dynamic of Mapalus. Researcher of ICRES.

Wardiman, Bagus. 2015. Pergeseran Nilai Sosial Mapalus Terhadap Ketahanan Sosial Wilayah (Studi Pada Masyarakat Desa Betelen I, Kecamatan Tombatu, Kabupaten Minahasa Tenggara, Provinsi Sulawesi Utara): Tesis. Yogyakarta: Universitas Gadjah Mada.

WAWOINTANA, T., \& Putra, H. S. A. (2001). Pelestarian mapulus di Minahasa dalam rangka pengembangan kebudayaan nasional:: Suatu tinjauan tentang sistem gotong royong, tolong menolong pada masyarakat di Kabupaten Minahasa. [Yogyakarta]: Universitas Gadjah Mada. 